\title{
Functions of MDMX in the Modulation of the p53-Response
}

\author{
Kristiaan Lenos and Aart G. Jochemsen \\ Department of Molecular Cell Biology, Leiden University Medical Center, P.O. BOX 9600, 2300 Leiden, The Netherlands \\ Correspondence should be addressed to Aart G. Jochemsen, a.g.jochemsen@lumc.nl
}

Received 5 October 2010; Accepted 21 January 2011

Academic Editor: Noel F. Lowndes

Copyright (C) 2011 K. Lenos and A. G. Jochemsen. This is an open access article distributed under the Creative Commons Attribution License, which permits unrestricted use, distribution, and reproduction in any medium, provided the original work is properly cited.

\begin{abstract}
The MDM family proteins MDM2 and MDMX are two critical regulators of the p53 tumor suppressor protein. Expression of both proteins is necessary for allowing the embryonal development by keeping the activity of p53 in check. Upon stresses that need to activate $\mathrm{p} 53$ to perform its function as guardian of the genome, p53 has to be liberated from these two inhibitors. In this review, we will discuss the various mechanisms by which MDMX protein levels are downregulated upon various types of stress, including posttranslational modifications of the MDMX protein and the regulation of $m d m x$ mRNA expression, including alternative splicing. In addition, the putative function(s) of the described MDMX splice variants, particularly in tumor development, will be discussed. Lastly, in contrast to common belief, we have recently shown the existence of a p53-MDMX feedback loop, which is important for dampening the p53-response at later phases after genotoxic stress.
\end{abstract}

\section{Introduction}

The tumor suppressor protein p53 is maintaining genome integrity following stress signals by either inducing a cell cycle arrest, allowing a complete checkup of the genome before resuming DNA replication, inducing senescence, or by stimulating apoptosis when the cell is beyond rescue [1]. In addition, p53 has been shown to directly affect DNA repair by modulating expression of number of DNA repair genes [2]. During tumor development, inhibition of angiogenesis is part of the tumor suppressor function of p53 [3]. In recent years, it has been shown that p53 also affects the metabolic switch which occurs in many tumors, in which energy is obtained by glycolysis rather than via oxidative phosphorylation [4]. p53 is activated by a plethora of stimuli, including DNA damage, hypoxia, and oncogene activation, the final outcome of the activation being very dependent on the strength and type of the stimulus and the type of targeted cell.

Whatever stimulus used to activate p53, it has become clear that for full, but controlled p53 activation, a tight control of activity and levels of the main p53 inhibitors, MDM2 and MDMX, is necessary [8,9]. Various mouse models provide the best evidence regarding the importance of MDM2 and MDMX in controlling p53 activity under normal conditions. Loss of either MDM2 or MDMX expression leads to embryonal lethality, which is rescued by simultaneous loss of p53. Tissue-specific deletion of either the $m d m 2$ gene or the $m d m x$ gene showed differences between cell types for their dependency on MDM2 and MDMX to keep p53 in check. These mouse models have recently been discussed in two excellent reviews $[9,10]$.

The MDMX and MDM2 proteins have a similar structural organization (Figure 1).

MDM2 and MDMX bind via their N-terminal hydrophobic region to a short alpha-helical stretch within the p53 N-terminus [11]; this $\mathrm{N}$-terminal region is best conserved between the two proteins. Other conserved structures include the C-terminal RING finger domain, a Zn-finger and a central acidic region. The RING finger domains of MDMX and MDM2 are involved in their homo- and heteromultimerization [12]. MDM2 has convincingly been shown to form both homo-oligomers and hetero-oligomers with MDMX. In contrast, no significant homo-oligomerization of MDMX could be found. This deficiency could have strong implications for the function of MDMX (see below).

MDM2 is an E3 ubiquitin ligase that targets p53 for ubiquitination and degradation. Essential for p53 ubiquitination are both the MDM2 C-terminal region including 


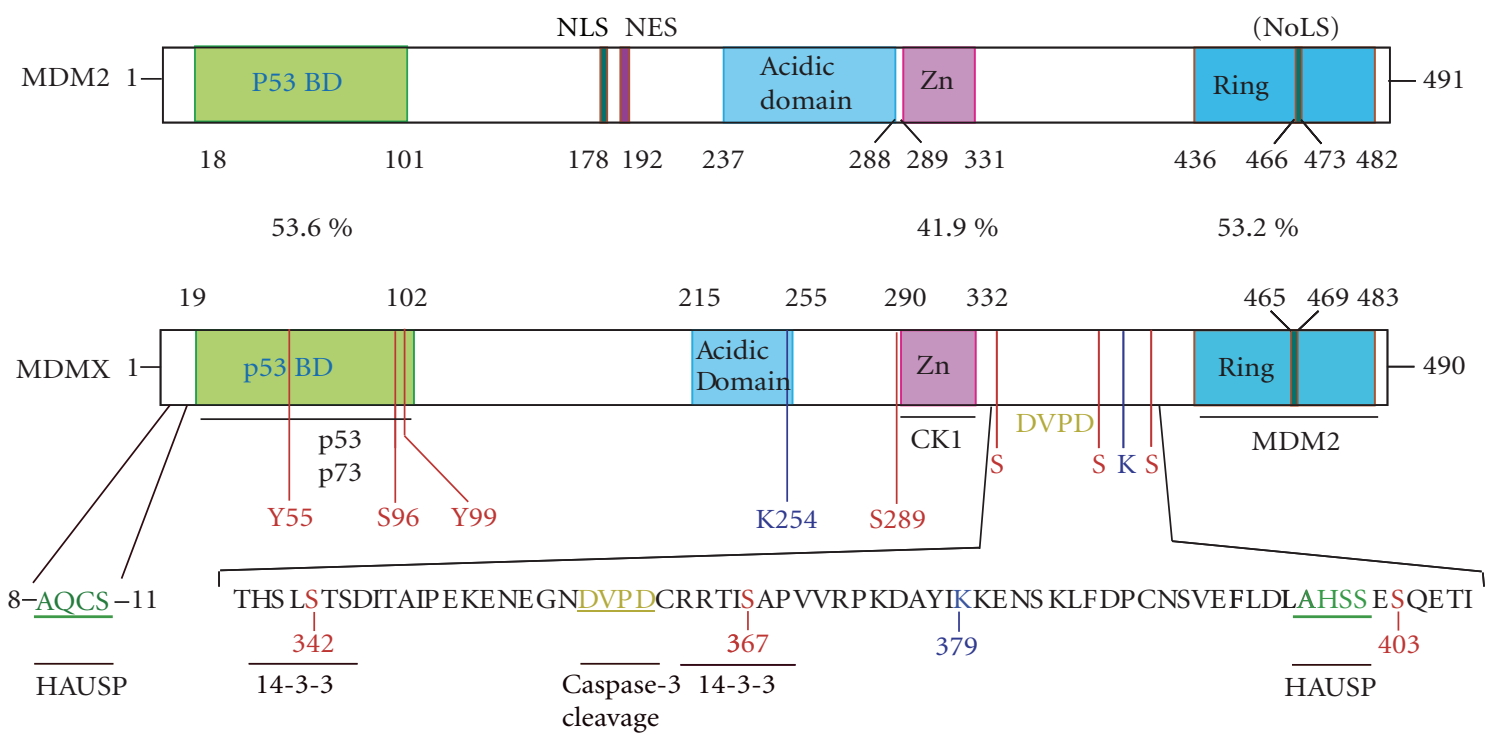

FIGURE 1: Schematic representation of MDMX protein structure in comparison with MDM2. Most indicated protein modification sites and protein-protein interactions shown are discussed in the text. Modifications of MDMX by sumoylation (K254, K379) have not yet shown to affect function or regulation of MDMX [5]. Phosphorylation of S298 stimulates the association of MDMX to p53 [6], and phosphorylation of S96 has been reported to affect the regulation of subcellular localization of MDM2 [7].

the RING finger and the acidic domain. Corresponding regions of MDMX cannot fulfill this function [13, 14]. MDM2-mediated monoubiquitination of p53 leads to nuclear export, thereby inhibiting the p53's function as a transcription activator. Moreover, it has become evident that Mdm2- dependent mono-ubiquitination of p53 promotes the localization of p53 to the mitochondria, where stressinduced HAUSP-p53 complexes result in nonubiquitinated, apoptotically active p53 [15]. Low levels of Mdm2 favor mono-ubiquitination of $\mathrm{p} 53$, leading to this mitochondrial transcription-independent induction of apoptosis upon stress. In contrast, high levels of Mdm2 and/or in combination with $\mathrm{p} 300 / \mathrm{CBP}$, promote polyubiquitination, which results in proteasome-dependent degradation of p53 [16, 17]. As mentioned, MDMX has no detectable ubiquitinligase itself, but has been proposed to inhibit p53 in a dual way. First, MDMX binds tightly to the N-terminal transcription activation domain of p53, in that way inhibiting its function as transcription activator [18]. Binding of MDMX to this part of p53 prevents the interaction of p300, which results in reduced acetylation of p53 which is involved in activation of p53 $[19,20]$. Interestingly, p300 acetylates several lysines at the $\mathrm{C}$-terminal region of $\mathrm{p} 53$ that are also targeted by Mdm2-mediated ubiquitination [17]. This might implicate that MDMX indirectly stimulates the MDM2-mediated ubiquitination by reducing the acetylation of those lysines. It should be noted that the importance of modifications of the $\mathrm{C}$-terminal lysines for correct regulation of p53 stability and activity in vivo appears to be limited. Krummel et al. [21] showed that a knock-in mutant mouse in which the C-terminal lysines were replaced by arginines developed normally. Several assays showed no difference in regulation of wild-type p53 and p53-7KR. Only a minor increased activation of p53 in the thymus upon ionizing radiation was found, and, interestingly, p53-7KR MEFs could not escape from senescence, in contrast to normal MEFs, indicating an increased activity of p53-7KR. The difficulty with interpretation of the results is that one cannot distinguish between the functions of the various possible modifications on the lysines (ubiquitination, sumoylation, neddylation, methylation, and acetylation). It could well be that a certain modification on one lysine counteracts the effect of a different modification on a nearby lysine. In Mdmx-deficient MEFs, we have seen increased acetylation of the one analyzed lysine in p53, K379. A full proteomic/mass spec approach would be interesting to analyze the ratio of various lysine modifications at the p53 C-terminus and the effect of different MDMX expression levels on that ratio.

What has become quite clear is that the ratio between the levels of MDM2/MDMX strongly determines the outcome on p53 stability. A relative high level of MDMX might compete p53 away from MDM2, leading to p53 stabilization [22]. In addition, as mentioned above, MDM2 and MDMX interact via their respective C-terminal RING finger domains, and it has been proposed that under nonstress conditions, the MDM2/MDMX heterodimer functions as a more active ubiquitin ligase via providing an extended interaction motif with the E2 protein [23-25]. One might argue that only a dimer/oligomer of MDM2/MDMX RING fingers can bind the E2; since MDMX cannot homodimerize, MDMX on its own is defective as a ubiquitin ligase. This might certainly be true, but is not the whole explanation since it has been shown that just replacing the MDMX RING with an MDM2 RING cannot rescue the ubiquitin-ligase activity of MDMX $[13,14]$.

In this review, we will focus on the regulation of MDMX expression upon various forms of stress. In most cases, 
a downregulation of MDMX protein is observed, which is needed for full p53 activation. On the other hand, under certain lethal conditions, a positive role for MDMX in p53-induced apoptosis has been found. These various and apparently contradictory results will be discussed. This includes the recently discovered p53-MDMX feedback loop, which affects the outcome of genotoxic insults in cells.

\section{MDMX Regulation upon Genotoxic Stress}

2.1. Inactivation of $M D M X$ at the Protein Level. Interestingly, initial reports indicated that MDMX levels were not affected by DNA damage or differentiation or during cell growth $[18,26]$. These wrong conclusions were caused by the absence of high-affinity antibodies and by our limited insight into the ways MDMX mRNA levels were regulated. The first to notice that DNA damage influences MDMX were $\mathrm{Li}$ and coworkers. They observed that DNA damage induces the nuclear translocation of exogenously expressed MDMX, but an effect on MDMX protein levels was not discovered [27]. Although it had been reported that MDMX could be degraded by a proteasome-dependent mechanism, which is enhanced by p53- and Adriamycin-induced caspasedependent cleavage of MDMX [28], only a year later it was recognized that MDMX is a target of the ubiquitin-ligase activity of MDM2 and that endogenous MDMX protein is degraded upon DNA damage, in an MDM2-dependent fashion [29-31]. Importantly, overexpression of MDMX prevented p53 stabilization and activation [31]. Notably, in these studies, no effect on the total amount of MDMX mRNA by ionizing radiation (10 Gy) was observed. Others and we subsequently showed that the MDM2-mediated degradation of MDMX is strongly stimulated upon ATM-dependent phosphorylations on three serine residues, S342, S367, and S403 [32-34]. These phosphorylations have multiple effects, including the temporal nuclear accumulation of MDMX in a 14-3-3-dependent manner [34-36].

Increased association of MDM2 with MDMX upon phosphorylation of the latter has been suggested [32] as an explanation for the increased ubiquitination and degradation of MDMX. Alternatively, we have shown that upon ATM-dependent MDMX phosphorylation, the interaction with the deubiquitinase HAUSP is strongly decreased and that HAUSP interaction/expression is needed to maintain endogenous MDMX levels [35, 37]. Whether the observed increased interaction with 14-3-3 proteins and the decreased interaction with HAUSP are causally related has not been proven. Interestingly, recently the interaction motifs for HAUSP on human MDMX have been mapped. It was found that both an $\mathrm{N}$-terminal motif $\left({ }^{8} \mathrm{AQCS}{ }^{11}\right)$ and more Cterminal motif $\left({ }^{398} \mathrm{AHSS}^{401}\right)$ in MDMX can interact with HAUSP [38]. The latter is very close to the S403, which is directly phosphorylated by ATM. Although not tested for this particular motif, it was found that phosphorylation of a serine residue two positions C-terminal of the core motif could strongly inhibit the interaction with HAUSP as assayed by peptide arrays. So, possibly both the direct phosphorylation event on S403, and the interaction of
14-3-3 around phosphorylated S342 and S367 are involved in decreasing the HAUSP/MDMX interaction.

Although one of the HAUSP interaction motifs in MDM2 is also close to the phosphorylation targets Y394 and S395, these phosphorylation events do not appear to affect the interaction with HAUSP [38]. Even though MDM2 lacks classic consensus sites for interaction, 14-3-3 proteins have also been shown to bind MDM2. Two sites have been mapped; one within the middle domain of MDM2, dependent on phosphorylation by Pim1-kinase on S166 and S186 [39]. However, this event appears to stabilize MDM2. On the other hand, 14-3-3 $\sigma$ was shown to interact with the RING finger domain of MDM2, in a phosphorylationdependent manner, and this interaction enhanced MDM2 ubiquitination and degradation [40]. Unfortunately, the involved phosphorylation events (target sites, signaling cascade) have not been investigated, but the 14-3-3 $\sigma$ interaction domain was found rather far downstream of S395, which is needed for the temporarily destabilization of MDM2 upon ionizing radiation [41]; so, a causal relation is not obvious. In addition, whether the observed effects on MDM2 stability are dependent on this specific isoform of 14-3-3 has not been extensively investigated.

The above-reported regulation of MDMX protein levels via ATM/Chk2 phosphorylations and 14-3-3/HAUSP interactions were all upon treatment of cells with IR or IR-mimetic NCS (neocarzinostatin). Surprisingly, UV-C induced DNA damage also increases phosphorylation of MDMX/Ser367 in a Chk1-dependent manner, but in this case, the increased interaction with 14-3-3 results in cytoplasmic sequestering of MDMX [42]. This manner of MDMX inactivation also turned out to be important for a full p53-stabilization upon DNA damage. Unfortunately, the authors did not investigate total levels of endogenous MDMX after longer time-points after UV-C irradiation; it is not excluded that the observed change in localization, seen three hours after UV-C, is a first step in the inactivation of the MDMX protein, followed by a total disappearance of fulllength MDMX protein either via proteasomal degradation or via alternative splicing of the MDMX pre-mRNA (see below). The physiological relevance of the UV-C mediated responses is questionable, since humans are not exposed significantly to UV-C. The use of UV-A or UV-B irradiation would have been better in that respect.

A recent elegant study with the use of a mouse knockin model has shown the importance of the S342, S367, and S403 MDMX phosphorylations, not only for a DNA damage response, but also in the regulation of tumor suppression by p53 [43]. As could be extrapolated from the cell culture studies, thymocytes or MEFs derived from the 3SA mutant mice show decreased degradation of MDMX upon ionizing radiation or neocarzinostatin treatment, and a concomitant reduced p53 stabilization and activation. More striking is the observation that crossing the 3SA mutant mice with $\mathrm{E} \mu$-Myc knock-in transgenic mice strongly decreased the latency period for tumor formation. In the developing tumors, no selection for p53 mutation was found in the 3SA mice, indicating that the expression of the mutant, degradation resistant MDMX is sufficient to inhibit p53's 


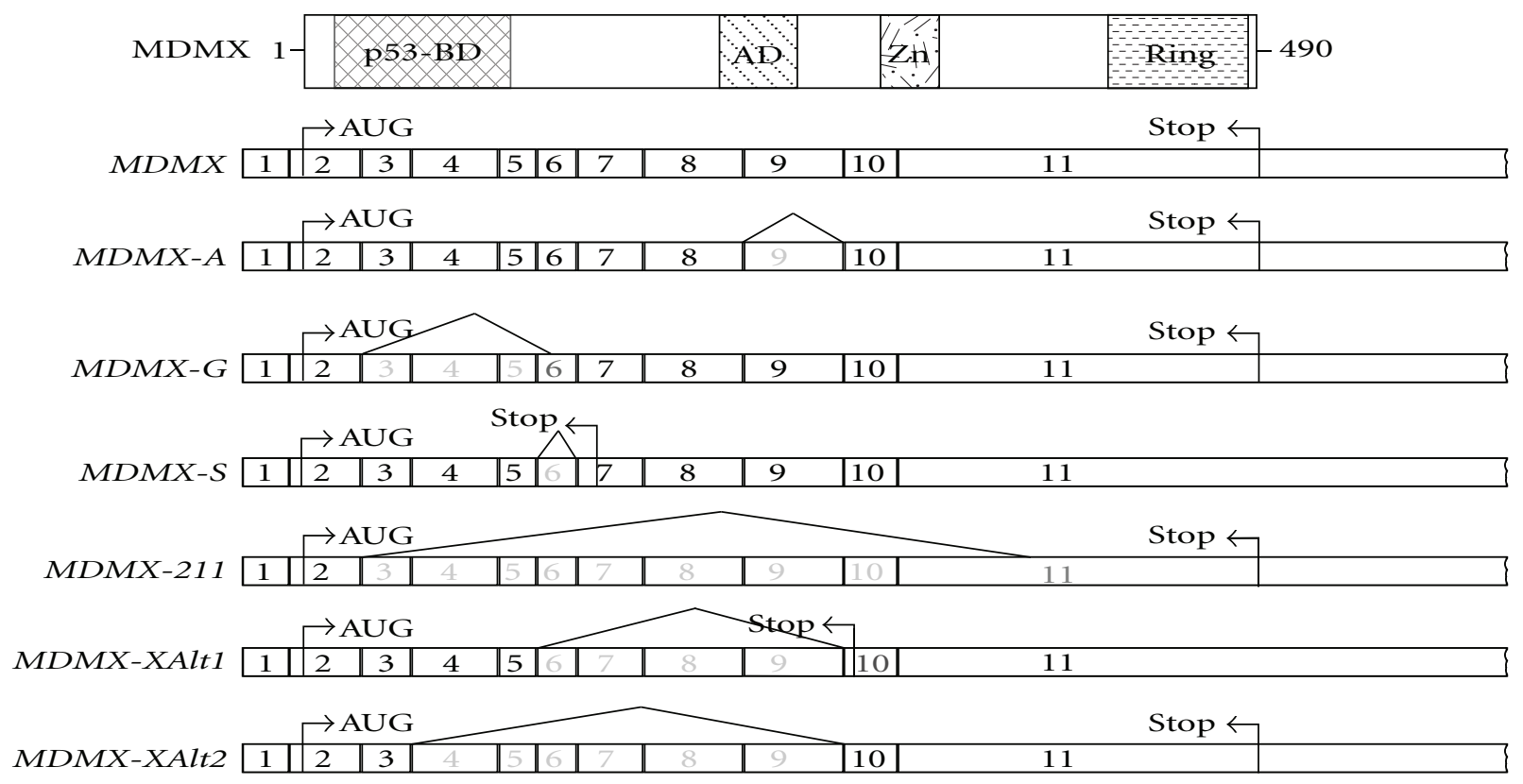

FIGURE 2: Schematic representation of the MDMX protein, the $m d m x$ mRNA and the reported $m d m x$ splicing variants.

tumor suppressor function. Although the involvement of other mechanisms cannot be excluded, it was found that the overexpression of the Myc transgene did result in activation of the double-strand DNA break DNA damage response, which could explain the observation that prevention of DNA damage-associated phosphorylations of MDMX impact on the tumor development [43]. It should be noted that it is not excluded that other, yet undefined, kinases are involved in the phosphorylation of MDMX which can be activated by Myc overexpression.

In addition to the serine phosphorylations mentioned above, also tyrosine phosphorylation of MDMX upon imposing double-strand DNA breaks has been reported [44]. Tyrosine 55 and tyrosine 99 were identified as targets of the $\mathrm{c}-\mathrm{Abl}$ tyrosine kinase. Phosphorylations on these sites increased upon DNA damage. Interestingly, Y99 phosphorylation was found to inhibit the p53/MDMX interaction, which was supported by structural modeling. Function of Y55 phosphorylation is not yet known, but appeared to be dependent on Y99 phosphorylation, and the authors suggest a possible role for Y55 phosphorylation in the recovery phase of p53 activation. These results indicate that double-strand DNA breaks not only targets MDMX to activate p53 via the ATM/Chk2 pathway to reduce MDMX levels, but also via a very quick pathway, c-Abl mediated phosphorylation that inhibits the MDMX/p53 interaction.

\section{Inactivation of MDMX at the Posttranscriptional mRNA Level}

Extensive alternative mRNA splicing of $m d m 2$ has been observed, especially in tumor cells [45]. In addition, existence of some splicing variants of $m d m x$ has also been reported, mainly in tumors/tumor-derived cell lines (reviewed recently by [46]). The so far identified $m d m x$ mRNA variants obtained by alternative splicing are depicted in Figure 2. Chandler and colleagues investigated whether genotoxic stresses would also affect the splicing pattern of $m d m 2$ and $m d m x$ [47]. It was observed that $m d m 2$ showed alternative splicing upon treatment with rather high doses of UV-C or cisplatin, but IR did not affect the splicing pattern. Similarly, $m d m x$ alternative splicing was observed upon 30 or $50 \mathrm{~J} / \mathrm{m}^{2}$ UV-C, but not with $10 \mathrm{~J} / \mathrm{m}^{2}$. Unfortunately, the effect of cisplatin treatment on $m d m x$ mRNA splicing was not tested in this study. What is missing from these studies is a clear quantification of the levels of the alternative spliced mRNAs compared to the normal spliced mRNA. Even better would have been to investigate whether the putatively produced alternative protein products are indeed synthesized endogenously. For MDMX that might be difficult, because only few high-quality antibodies are available, but for MDM2 it could have been performed. Possible functions of the protein products of splicing variants have been investigated almost only by strong overexpression, which might not reflect the physiologically relevant situation. Therefore, no conclusions can be drawn regarding a physiological function of the alternative splicing after these high levels of DNA damage. The authors note that they also detect low levels of another $m d m x$ splicing variant, $m d m x-S$ [47]. This splicing variant, a result of exon 6 skipping, was first described by Rallapalli and colleagues [48]. The alternative splicing was mainly found in some cancer cell lines and could be increased in nontransformed cells upon serum-stimulation. The $m d m x-S$ mRNA encodes essentially only the p53 binding domain, and a number of unique C-terminal amino acids (Figure 2). In overexpression studies the MDMX-S product was found to be a stronger inhibitor of p53 activity, most likely because this short 


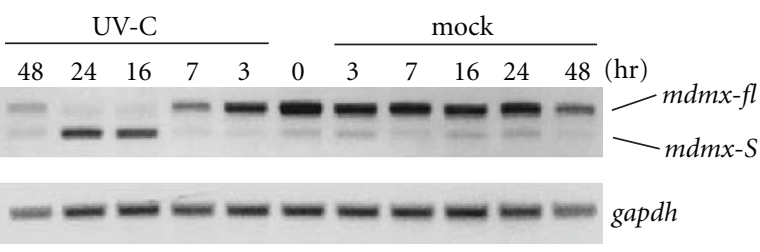

Human skin fibroblasts

(a)



U2OS

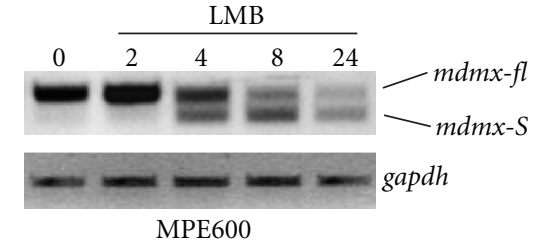

MPE600

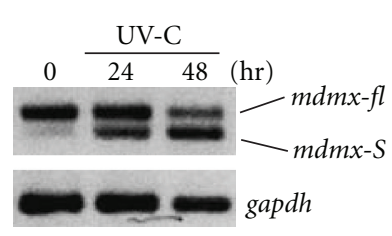

MCF-7

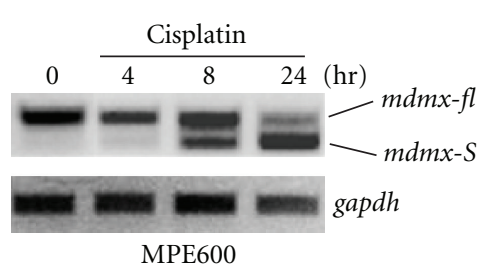

(c)

(b)

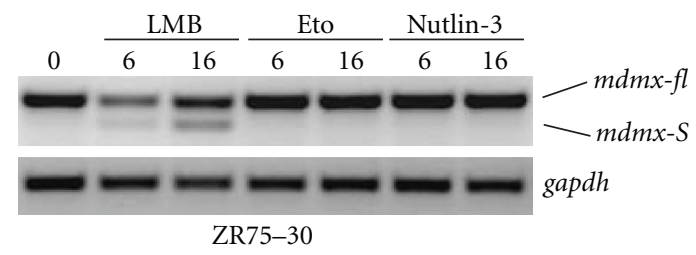

(d)

FIgURE 3: The ratio between $m d m x-S$ and $m d m x-f l$ mRNA is increased by various types of DNA damage and by inhibition of nuclear export. RT-PCR analysis of RNAs extracted from various cell lines, treated for the indicated time periods with a variety of agents. The $m d m x$ specific PCR primers are located in exon 3 and exon 8 . The doses genotoxic/drug treatments used: UV-C: $15 \mathrm{~J} / \mathrm{m}^{2}$; cisplatin: $30 \mu \mathrm{M}$; LMB (Leptomycin B): $10 \mathrm{nM}$; Eto (Etoposide): $20 \mu \mathrm{M}$; Nutlin-3: $10 \mu \mathrm{M}$.

protein localized into the nucleus much more efficiently than full-length MDMX [49].

Importantly, in recent experiments, we found that after exposure of normal human fibroblasts or MCF-7 cells to relatively low levels of UV-C $\left(10 \mathrm{~J} / \mathrm{m}^{2}\right)$, splicing of $m d m x$ mRNA is changed, but that preferentially the $m d m x-S$ variant is expressed (Figure 3). This is a relative quick event in the human skin fibroblasts and occurs somewhat slower in the MCF-7 cells. Under these conditions, the X-Alt1 and $X$-Alt2 splice variants as described by Chandler et al. [47] could not be detected. In addition, we found that cisplatin $(30 \mu \mathrm{M})$ strongly induced the switch in ratio between fulllength $m d m x$ - and $m d m x$-S mRNAs in the breast carcinoma MPE600 cell line (Figure 3). Similar results were obtained in other tumor cell lines, such as U2OS, upon treatment with comparable concentrations cisplatin or with $20 \mu \mathrm{M}$ doxorubicin (data not shown).

At the moment it is not known via which mechanism alternative splicing of $m d m x$ is induced upon genotoxic stress. From the literature, a few mechanisms can be proposed. First, it has been shown that upon stress the subcellular localization of proteins involved in splice site selection is affected, like the hSlu7 protein ( $3^{\prime}$ site selection) and the hnRNP A1 proteins ( $5^{\prime}$ site selection). Treatment of cells with osmotic shock or UV-C leads to cytoplasmic localization of hnRNP A1, which affects the choice of $5^{\prime}$ splice site [50]. Since with $m d m x$ the change is the choice of the $3^{\prime}$ splice site, involvement of hSlu7 is more likely [51]. However, in that publication, it is mentioned that cisplatin treatment does not affect hSlu7 subcellular localization, so regulation of hSlu7 is most likely not the single mechanism by which the splicing of $m d m x$ mRNA is altered. More recently, it was reported that alternative splicing upon UV$\mathrm{C}$ treatment is coregulated with the inactivation of RNA polymerase II by inducing the hypophosphorylation of the CTD region [52]. Although such a mechanism cannot be excluded at the moment in the alternative splicing of $m d m x$ mRNA, changes in subcellular localization of certain factors involved in splicing are likely to play a role in the alternative splicing of $m d m x$ mRNA. We have found that the treatment of several types of cells with Leptomycin B, which blocks nuclear export of proteins containing a Rev-like nuclear export signal, strongly increases alternative splicing of $m d m x$, leading to increased levels of $m d m x-S$ mRNA and reduced $m d m x$ full-length mRNA (Figure 3 ), accompanied with a reduced MDMX protein level (not shown).

Even so, it is unclear what the biological importance of this alternative splicing is. It can be a means to reduce the amount of full-length MDMX protein (which indeed is found after sublethal doses of UV-C $[31,53]$ ), needed for full activation of p53. In this case, alternative splicing would lead to a loss of function. On the other side, it could be a mechanism to produce an MDMX protein form that is resistant to MDM2-mediated degradation, which could have a function in attenuating the p53 response at later timepoints after the damage. In that case, it would be a gain of function.

Putative biological functions of protein products of the $m d m x$ splicing variants will be discussed later.

Markey and Berberich [54] have recently uncovered another mechanism leading to reduction of MDMX protein levels upon genotoxic agents. They found that exposing cells to doxorubicin $(0.5 \mu \mathrm{g} / \mathrm{mL}$; which is $\sim 0.85 \mu \mathrm{M})$ leads to a strong reduction in the total $m d m x$ mRNA levels; this effect was found to be fully p53-independent. Similarly, cisplatin reduces $m d m x$ mRNA levels in doses varying from 25 to $100 \mu \mathrm{M}$, on various cell lines, independent of their p53 status. In addition, the authors show that the decrease of MDMX protein levels after doxorubicin treatment could not efficiently be rescued by proteasome inhibition or knockdown of p53 and MDM2, when measured $24 \mathrm{hrs}$ after start of treatment. It would have been nice if the authors would 
have shown a time-course of doxorubicin treatment and analyzed both MDMX protein and mRNA. It could well be that initially degradation of the MDMX protein occurs upon the activation of the DNA damage signaling cascade, and that the reduced mRNA level is a later effect. These authors also investigated the alternative splicing of $m d m x$ mRNA upon doxorubicin treatment. The remarkable observation here is that for this experiment they use a $100 \mu \mathrm{M}$ concentration of doxorubicin, which is more than 100-fold higher than used in their initial experiment; so, it cannot be compared to the earlier experiment. It could be, but that is not commented upon, that at the lower concentration of doxorubicin no significant alternative splicing can be found. Anyway, the authors do find some increase in $X$-Alt2 levels, but actually a small decrease in X-Alt1. Again, total levels of $m d m x$ mRNA strongly decrease, indicating that $X$-Alt 2 only represents a very small fraction of the total $m d m x$ mRNA. Interestingly, the decrease in $m d m x$ mRNA levels is caused by decreased stability of the $m d m x$ mRNA. The authors suggest a putative involvement of microRNA miR-34a in this regulation of $m d m x$ mRNA stability. This is interesting in the view of the earlier observation that transcription of the miR34 family members is upregulated upon p53 activation, which has been shown to be important for a full p53 response upon DNA damage $[55,56]$. However, the regulation of miR-34a by p53 does not explain the p53 independency of the $m d m x$ mRNA destabilization upon DNA damage. Unfortunately, it was not addressed in this study whether the decrease in $m d m x$ mRNA after doxorubicin or cisplatin treatment is important for the biological outcome of the treatment. So, the physiological importance of the observed $m d m x$ mRNA reduction still has to be investigated.

\section{A Proapoptotic Function of MDMX upon Lethal Doses of Stress}

In all the experiments presented above, the idea was that a decrease in MDMX expression is needed to get a fullblown p53-response upon DNA damage. And indeed, in most cases, a decrease in MDMX levels is observed and some experiments have shown that prevention of that MDMX degradation is inhibiting the $\mathrm{p} 53$ response $[31,35]$. However, these experiments were all done with a sublethal dose of IR or treatment with IR-mimetic agents like NCS.

The group of Fabiola Moretti has obtained results that appear to be in conflict with what has been discussed above. In an initial report, it was presented that in an (inducible) overexpression system high levels of MDMX actually stimulate doxorubicin (adriamycin)-induced apoptosis [57]. This correlated with an increased induction of Bax transcription, while p21WAF1 was induced similarly in control- and MDMX-overexpressing cells, suggesting that high MDMX expression facilitated p53-mediated induction of proapoptotic genes specifically. These experiments were all performed with the use of nontransformed mouse or human cells, with doxorubicin as the genotoxic agent. The main drawback of this study is that a pro-apoptotic function of endogenous levels of MDMX protein was not investigated.
Furthermore, it could be that MDMX has a different function in untransformed versus tumor cells upon adriamycintreatment. In this respect, it is of interest to note that in the colorectal tumor cell line HCT116 an active p53 seems to inhibit adriamycin-induced apoptosis [58], so a pro- or antiapoptotic function of MDMX could very well be strongly cell type specific.

In a follow-up study, the authors made the very intriguing observation that a fraction of MDMX is localized to the mitochondria and that upon lethal stress MDMX could function as an anchor for S46-phosphorylated p53, leading to transcription-independent apoptosis [53]. Unfortunately, the genotoxic agents used were now UV-C and cisplatin, which makes comparison with the earlier publication difficult. Strikingly, it was found that low levels of UV-C irradiation did reduce MDMX protein levels in MCF-7 cells, but that high, lethal doses $\left(40 \mathrm{~J} / \mathrm{m}^{2}\right)$ of UV-C did not or much less. At these high doses, reduced levels of MDM2 were found, fitting with earlier reports that lethal doses of genotoxic agents can inhibit $m d m 2$ transcription $[59,60]$, partly by activation of HIPK2 [61, 62]. The results also lead to two tentative conclusions. First, the observed alternative splicing of $m d m x$ mRNA after high UV-C doses in MCF-7 cells [47] would not lead to a reduction in full length MDMX protein. Second, under these conditions the earlier reported downregulation of $m d m x$ mRNA levels upon genotoxic stress [54], admittedly a different type, is not occurring.

Most strikingly in this study is the observation that reducing MDMX levels by siRNA did decrease the induction of apoptosis upon UV-C irradiation. A similar result was obtained upon treatment of control- and MDMXknockdown MCF-7 cells with $\alpha$-amanitin, which blocks polymerase II transcription but is reported to induce a p53dependent apoptosis strictly by stimulating translocation of p53 to the mitochondria.

Similarly, reducing MDMX levels in A2780 cells partly prevents cisplatin-induced apoptosis ( $20 \mu \mathrm{M}$ cisplatin). This concentration of cisplatin did not induce significant alternative splicing of $m d m 2$ mRNA in MCF-7 or U2OS cells [47]. The effects on $m d m x$ mRNA were not investigated in this study, but a similar dose of cisplatin $(25 \mu \mathrm{M})$ caused a small upregulation of $m d m x$ mRNA in MCF-7, but already a downregulation in some other cell lines [54]. We found recently in a few osteosarcoma cell lines that $20 \mu \mathrm{M}$ cisplatin reduces the total levels of $m d m x$ mRNA and increases the $m d m x-S$ : $m d m x-F L$ ratio, independent of the p53 status (Lenos et al., manuscript in preparation).

It is difficult to reconcile the data from Moretti and colleagues with the earlier presented data. However, there are a number of points to keep in mind. The data obtained with ionizing radiation or IR-mimetic usually did not induce a high level of apoptosis, but mainly a cell cycle arrest. When UV-C was used, it was at relative low doses (5 or $10 \mathrm{~J} / \mathrm{m}^{2}$ ), which might give some apoptosis induction, but not very high. The alternative splices as described by Chandler et al.(2006) [47] were only seen at rather high doses of UV-C or cisplatin; these are in the same range as Moretti and colleagues used, but Chandler et al. did not investigate effects on protein levels. What can be noticed from that study 
is that while the dose of UV-C resulted in almost complete alternative splicing of $m d m 2$ mRNA (full length is hardly detectable anymore), the main $m d m x$ mRNA expressed upon treatment with $50 \mathrm{~J} / \mathrm{m}^{2}$ UV-C is still the ful-length mRNA. So, it is possible that under these ruthless conditions MDMX protein is still expressed.

What we do find somewhat surprising, though, is that apparently the induction of apoptosis by $40 \mathrm{~J} / \mathrm{m}^{2}$ is largely dependent upon the targeting of p53 into the mitochondria. In several cellular systems, it has been reported that UV$\mathrm{C}$ (and cisplatin) can induce apoptosis in p53-null or p53mutant cells [52, 63-65], indicating that wild-type p53 status is not a universal essential factor for UV-C or cisplatininduced apoptosis. It will be interesting to see whether modulation of MDMX levels in p53-deficient cells also affects the UV-C or cisplatin-induced apoptosis.

In an attempt to understand and reconcile the various and sometimes contradicting results, a very well-structured study should be performed in which one or two wildtype p53 expressing cell lines, if possible with their p53deficient counterparts, were treated with various types of stress-inducing agents, mainly genotoxic agents like doxorubicin, cisplatin, IR, and UV-C irradiation, but also with a Polymerase-II transcription inhibitor like $\alpha$-amanitin. Cells should be extensively analyzed at early and late time-points for expression of relevant genes (p53, MDM2, MDMX, p53targets) at protein and mRNA level (including analyses of splicing variants) and for the biological outcome of the treatment. The latter can be done primarily by FACS analyses to determine DNA profile (PI staining), apoptosis (Annexin $\mathrm{V}$ staining), and DNA replication (BrdU incorporation). The importance of MDMX regulation can be determined by using MDMX knockdown derivatives of the used cell lines. Such a study should be able to provide the answers to several questions regarding the regulation of MDMX by the various agents, and the importance of that for the biological response.

\section{Role of MDMX in the Ribosomal Stress Response: Essential Part of the DNA Damage Response?}

In the last years, a strong link between nucleolar- and ribosomal stress and p53 activation has been established. Very importantly, Rubbi and Milner showed that disturbance of nucleolar integrity is important for the DNA damage response [66]. As such, they already showed that the DNA damage response and ribosomal stress are causally linked. Several groups subsequently showed that upon nucleolar disruption, ribosomal proteins are released, and several of those interact with MDM2 and prevent the MDM2-mediated degradation of p53 (recently reviewed by $[67,68]$ ). Very striking, none of the ribosomal proteins shown to interact with MDM2 interact with MDMX, suggesting a selective targeting by ribosomal proteins [69]. However, that does not imply that MDMX is not important for the ribosomal stress response. Indeed, these researchers show that upon treatment of cells with Actinomycin D or 5-FU, at concentrations that are reported not to induce a significant DNA damage response but only to give ribosomal stress, MDMX levels are downregulated. Importantly, that downregulation is needed for full p53 activation. The MDMX degradation is MDM2-dependent, but is not associated with increased phosphorylation of MDMX-Serine367, so is distinct from the ATM/Chk2-stimulated MDMX degradation. Interestingly, the treatment with these compounds leads to release of L11 protein from the nucleoli, which binds MDM2 and inhibits MDM2-mediated degradation of p53, but stimulates the MDMX ubiquitination by MDM2 [69]. MDMX overexpressing cells showed an increased resistance to apoptosis induction by $5-\mathrm{FU}$, and indeed MDMX also inhibited the growth-suppressing effects of 5-FU on xenografts of HCT116 cells. Also in this case words of caution are needed. In the model tested, the HCT116 cells, the 5-FU effects are largely dependent on wild-type p53 function, as shown earlier [58]. However, other studies indicate that the effects of 5-FU on colorectal tumor cells are only very limited dependent on p53 status, and then only at really low concentrations [70]. Furthermore, in a small panel of 4 breast cancer cell lines, all expressing wild-type p53 and sensitive to Nutlin-3, only two showed a partial p53-dependence on growth inhibition by $5-\mathrm{FU}$, while one cell line actually is sensitized for 5 -FU by reduced p53 levels [71]. The differential effects can possibly in part be explained by a difference in $\mathrm{pRB}$ status, which seems to dictate the dependence of 5-FU responsiveness on wild-type p53 status [72]. Therefore, it would be of importance to investigate whether in other settings (e.g., p53 proficient, but pRB-deficient) MDMX levels also have an impact on 5-FU sensitivity.

A recent study from the Prives' lab showed another cross-talk between ribosomal proteins and MDM2/MDMX regulation of p53 [73]. They identified the small ribosomal subunit protein S7 as an MDM2-interacting protein, which can inhibit the MDM2-mediated degradation of p53. Interestingly, they found that $\mathrm{S} 7$ could only perform its function efficiently in the presence of MDMX. A putative involvement of S7 in MDM2-mediated degradation of MDMX was not investigated. A striking observation of these investigators was also that knockdown of either the ribosomal protein L11 or S7 attenuated the p53 activation not only by agents inducing ribosomal stress, but also DNA damaging agents like doxorubicin and neocarzinostatin. These data confirm the earlier mentioned observations by Rubbi and Milner, who already showed that DNA damage only affects p53 stability when it is causing nucleolar disruption [66].

\section{Alternative Splicing of MDMX mRNA: What Is Its Use?}

At the moment, 6 different splicing variants of MDMX have been described, which are schematically depicted in Figure 2. As mentioned before, the first reported splicing variant is the $m d m x-S$ mRNA, expression of which seemed to correlate with transformed cells and with normal cells stimulated to grow after serum-stimulation [48]. This was attributed to the fact that MDMX-S protein, which essentially comprises 

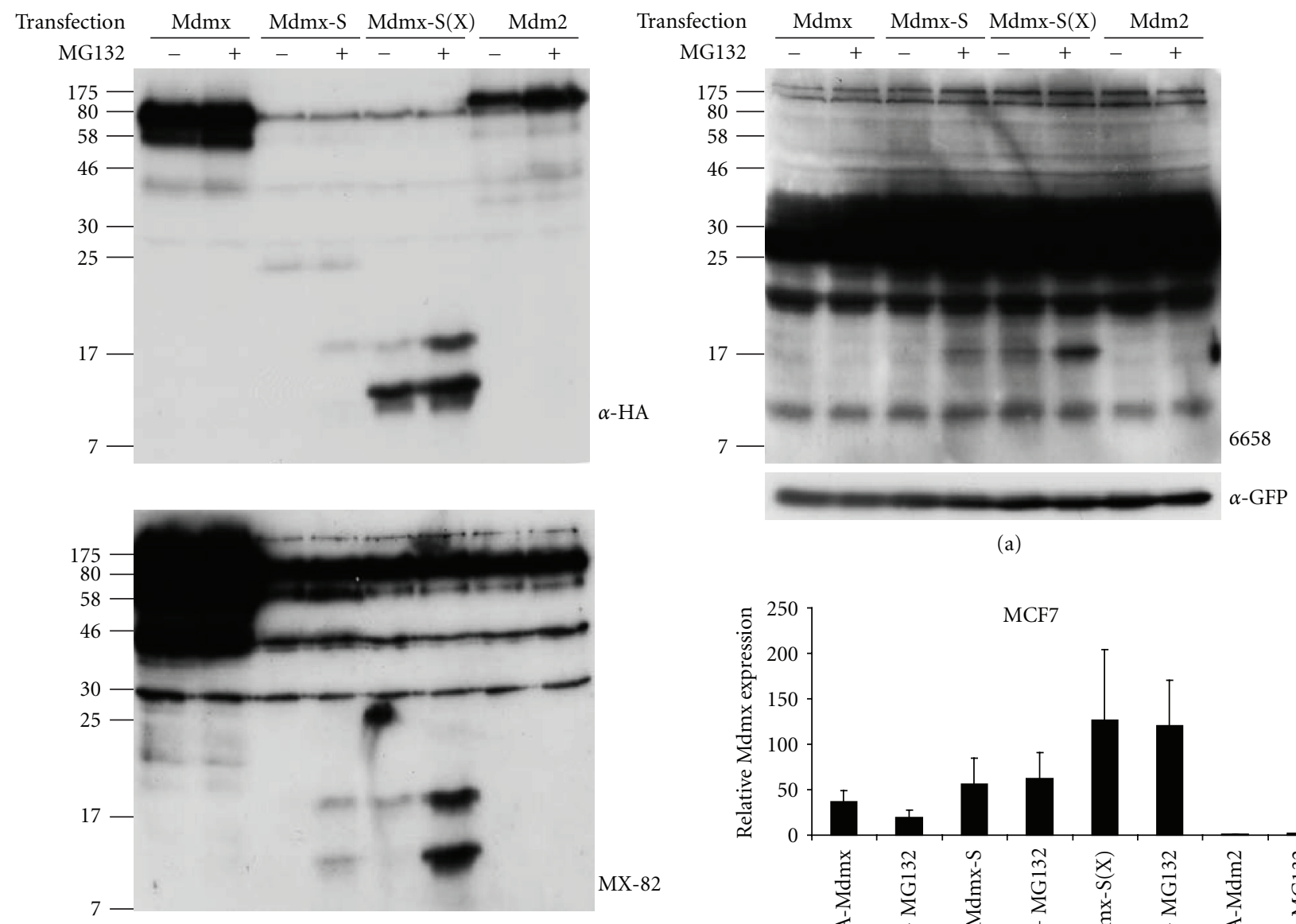

(a)

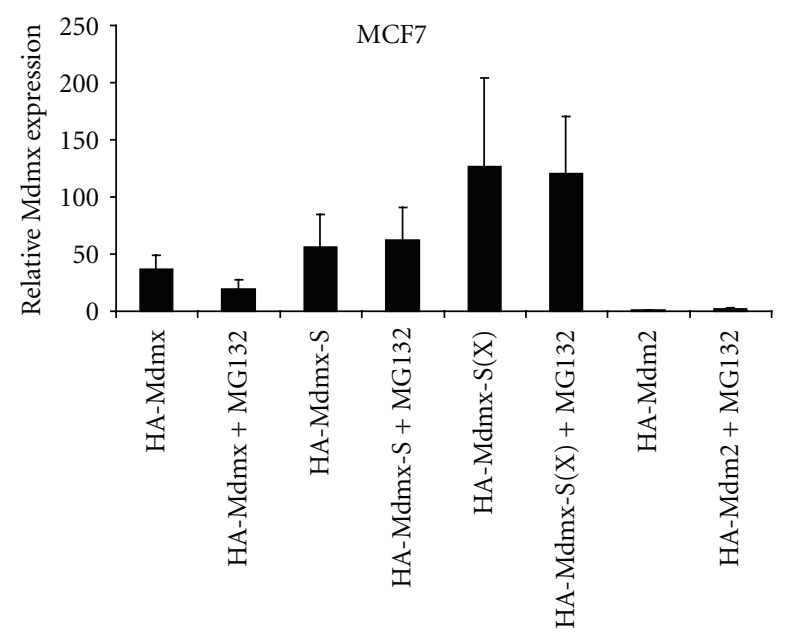

(a)

(b)

Figure 4: Expression of Mdmx-S protein is much lower compared to full-length Mdmx and increased upon MG132 treatment, whereas mRNA levels are even higher in transfection studies. MCF7 cells were transfected with the indicated constructs (6-well plates; $1 \mu \mathrm{g}$ of each construct/well; all well were also transfected with $250 \mathrm{ng}$ of CMV-eGFP expression vector as transfection control). Twenty four hrs after transfection, the cells were either mock treated or treated with $20 \mu \mathrm{M}$ MG132 for 7 hours. Cell lysates were analyzed by Western Blotting with the indicated antibodies (6658 = MDMX-S specific antibody) and extracted RNA was analyzed by quantitative real-time RT-PCR.

only the p53-binding domain (amino acids 1-114), and 26 unique C-terminal amino acids, is a stronger inhibitor of p53 as assayed by overexpression studies [49]. What is important to note is that the authors denote a protein of about $32 \mathrm{kDa}$ in COS cells as the endogenous MDMX-S protein, which is significantly larger than the predicted molecular weight of approximately $16 \mathrm{kDa}$. The authors propose that this shift is caused by post-translational modification of the MDMX-S protein, but the type of modification was not determined. Strikingly, in vitro translation of the $m d m x-S$ mRNA yielded also the $32 \mathrm{kDa}$ protein, and a protein of about $17 \mathrm{kDa}$, which could represent the "real" MDMX-S protein. We have recently obtained evidence that the $32 \mathrm{kDa}$ protein is most likely not representing the true MDMX-S protein.
Transfection of an MDMX-S expression vector, encompassing the total MDMX coding region but just lacking exon 6, with an N-terminal HA-tag, results in expression of a protein around $24 \mathrm{kDa}$ detected with anti-HA antibody (Figure 4). Expression level of this protein is much lower than that of full-length HA-MDMX protein upon transfection of the same amount of plasmid DNA. In addition, smaller proteins around $18 \mathrm{kDa}$ and $14 \mathrm{kDa}$ are found, which are even lower expressed. However, we also made an expression vector in which we truncated the $m d m x$ cDNA at an XbaI restriction site, just downstream of the predicted stop codon of MDMX-S protein in exon 7. So, this construct theoretically has the same coding potential. When this construct is expressed, only the smaller proteins of 
about 18 and $14 \mathrm{kDa}$ can be detected with anti-HA, again at low levels compared to full-length HA-MDMX. Importantly, an antibody raised against the $\mathrm{C}$-terminal unique amino acids of MDMX-S (Frank Bartel, personal communication) recognizes only the $18 \mathrm{kDa}$ protein, identifying that as the real MDMX-S protein. The anti-MDMX antibody MX82, with its epitope around amino acid 100 of MDMX, recognizes both the $18 \mathrm{kDa}$ and $14 \mathrm{kDa}$ protein, but not the $24 \mathrm{kDa}$ protein. Two conclusions can be drawn from these results. First, the $24 \mathrm{kDa}$ protein, possibly reflecting the $28 \mathrm{kDa}$ protein mentioned by Rallapalli et al. [48], is most likely an artifact of the overexpression of the $m d m x-S$ cDNA, because it appears to lack the MX-82 epitope which should be included in the MDMX-S protein. Secondly, the smaller protein of about $14 \mathrm{kDa}$ lacks a C-terminal part of MDMX-S; again most likely some artifact of the overexpression. Importantly, when we use the same expression plasmids for in vitro translation, we only detect the $18 \mathrm{kDa}$ protein, either with an anti-MDMX antibody (1328; raised against bacterially produced MDMX-S protein) or with antiMDMX-S specific antibody (Figure 4). In addition, His6tagged bacterially produced MDMX-S protein also has an apparent molecular weight of about $18 \mathrm{kDa}$.

As mentioned, we find that the MDMX-S protein is much lower expressed compared to full-length MDMX, in contrast to previous reports, but confirming our previous finding [20]. This is not a result of transfection efficiency, as can be seen by the expression of the transfection control (Figure 4), and similar results were obtained after transduction of cells with lentiviral expression vectors for MDMX-S (not shown). Furthermore, real-time Q-PCR analysis showed that $m d m x-S$ mRNA was even higher expressed than fulllength $m d m x$ in these transfections (Figure 4(b)). Notably, treatment of transfected or transduced cells with proteasome inhibitor MG132 strongly increased the MDMX-S protein level, suggesting that the protein is very unstable. The levels of full length MDMX protein are only mildly increased upon MG132 treatment, while no effect is seen on the $24 \mathrm{kDa}$ protein. Although we have no evidence at the moment, the rapid degradation of MDMX-S is possibly caused by the unfolded protein response (UPR); it is possible that this truncated MDMX protein is not properly folded, and as such is targeted via UPR for degradation.

In addition, we have put much effort in detecting the endogenous MDMX-S protein, which we expected not to be such a problem because the recently developed monoclonal antibody, MX-82, has its epitope within the MDMX-S region. However, even in cell lines that express more $m d m x$ $S$ mRNA compared to $F L-m d m x$ mRNA, only full-length MDMX protein can be detected (data not shown). Therefore, we propose that the induction of $m d m x-S$ mRNA is a means of reducing full-length MDMX levels, and not so much the generation of a new MDMX Figure 3, where it can be seen that full-length $m d m x$ mRNA decreases as $m d m x$ $S$ mRNA levels increase upon various stress conditions, whereas MDMX-S protein levels are still undetectable (not shown).

The MDMX-A and MDMX-G variants were cloned from C33A cells, a somewhat exceptional cell line in that it expresses high levels of mutant p53 but also high levels of MDMX [30]. The corresponding MDMX proteins could not unequivocally be identified, no biological function has been determined, and whether this particular splicing event is affected by any event, like stress conditions, is unknown. Therefore, these splicing variants will not be discussed here any further.

As mentioned above, UV-C irradiation was found to lead to alternative splicing of MDMX, resulting in X-Alt1 and $\mathrm{X}$-Alt2. Again, no functional studies have been performed, synthesis of predicted alternative MDMX proteins has not been investigated, and the ratio between the full-length MDMX and the alternative splicing variants is not known. Therefore, a biological relevance of these splicing variants is still hypothetical.

Giglio and colleagues are the only group to report functional experiments on an endogenously expressed MDMX splice variant [74]. They identified an $m d m x$ mRNA variant, which they called $m d m \times 211$, in a thyroid tumor cell line (ARO), which has structural similarity to the $X$-Alt2 variant (see Figure 2). The protein products produced by these variants both lack the major part of the p53-binding domain, but still contain the C-terminal domain including the RING finger. A difference is that the $X$-Alt2 variant contains all exon 11 encoded amino acids, including the $\mathrm{Zn}$-finger, while the $m d m \times 211$ variant lacks the $\mathrm{N}$-terminal part of the exon 11. Overexpression experiments indicate that MDMX211 protein can stabilize MDM2 and prevents the degradation of p53 by MDM2, reflecting what has been published about full-length MDMX protein [75]. Overexpression of MDMX211 increased colony formation of both p53-wt and p53-negative cells, indicating a p53-independent oncogenic role of MDMX211. Physiologically more relevant is the specific knockdown of this MDMX variant in ARO cells. Reducing levels of $m d m \times 211$ mRNA about 50\% reduces the viability of this cell line, suggesting that both fulllength MDMX and the alternative MDMX211 form are contributing to the proliferation of these cells. However, the effects of specific knockdown of full-length MDMX was not investigated in parallel, nor were relative levels of MDMX and MDMX211 proteins compared. Knockdown of MDMX211 did reduce MDM2 levels, but p53 levels or activity was not investigated, probably because these cells harbor a mutant p53. Again, these results are indicating a p53-independent oncogenic function of MDMX211. It is unfortunate that the authors have not studied the effect of specific knockdown of MDMX211 and full-length MDMX in the FRO cell line, which appears to express similar levels of MDMX211, but contains a wild-type p53 gene [76]. The comparison between MDMX211 and FL-MDMX in this cell line would especially have been interesting in the experiment investigating the sensitivity to adriamycin treatment. As mentioned earlier, Mancini and colleagues published that overexpression of full length MDMX could increase the sensitivity to adriamycin [57]; so, one would predict that knockdown of MDMX would increase the number of viable cells after adriamycin treatment. This would then indeed be opposite from the effects of knockdown of MDMX211 in ARO cells, which increases the sensitivity to adriamycin in 
these thyroid tumor cells [74]. All in all, these results indicate that MDMX-211 has oncogenic potential, but whether that is increased compared to full-length MDMX is not known at the moment.

A number of studies investigated the expression levels of $m d m x$ mRNA and of $m d m x$ splicing variants in a panel of tumors. An analysis of malignant gliomas showed an amplified $m d m x$ gene in a subset of tumors, none of which had p53 mutation. Interestingly, ratio between $m d m x$ $S / m d m x-F L$ mRNA was found to be significantly higher in grade IV glioblastomas compared to grade III anaplastic gliomas or grade II gliomas [77]. Bartel and colleagues studied 66 soft tissue sarcomas for $m d m x$ gene amplification and $m d m x-F L / m d m x-S$ mRNA expression [78]. They also found an association between tumor grade and overexpression of the $m d m x-S$ splice form. Furthermore, from their analyses they concluded that the $m d m x-S$ is a prognostic factor that predicts a poor outcome and a significantly shortened survival time for STS patients. No correlation between p53 status and $m d m x-S$ expression was evident. Keeping in mind that our analyses so far suggest that increase in the ratio of $m d m x-S$ mRNA compared to $m d m x-F L$ mRNA is more a means to decrease full-length $m d m x$, it could imply a tumor suppressor function for the MDMX protein, as is also suggested from the study of Moretti and colleagues [79]. They found that in 57 papillary thyroid tumors, which all contain a wild-type p53 gene, a decrease of full length MDMX is associated with tumor stage (stage 1 versus others), indicating downregulation of MDMX protein levels during tumor progression. An increased ratio $m d m x-$ S: $m d m x-F L$ (ratio $\geq 1.5$ ) mRNA is found in a significant percentage of these thyroid tumors, but is not associated with any clinical data. Expression of the $m d m \times 211$ mRNA is also found in a subset of tumors, again not correlating with any patient data. Together, these data on the expression of $m d m x$-FL and $m d m x$ mRNA splice variants in combination with other analyses of $m d m x$ gene amplification, $m d m x$ mRNA expression and MDMX protein analyses in tumors [80-83] strongly indicate that the function of MDMX in tumorigenesis is strongly dependent on the tumor type. Although in several tumor types MDMX appears to have an oncogene function, in others it seems to be antioncogenic. So far, the study by Moretti and colleagues has been the only indicating a tumor suppressor role of MDMX in wild type p53 expressing human tumors; unfortunately, the authors do not show any data on the levels of p53 in these tumors. Possibly, the p53 gene is still wild type but the expression of the p53 mRNA is silenced yielding an essential p53-null tumor. This is important in the light of other publications in mouse models indicating an antiproliferative function of MDMX $[84,85]$. In the first study a growth suppressive function of mouse MDMX in a p21 $1^{\mathrm{WAF} 1}$-deficient background was observed [84]. In addition, in a p53-null background loss of MDMX increased the growth of mouse embryo fibroblasts and endogenous levels of MDMX suppresses tumorigenicity in p53-null mice [85]. In p53-null cells, MDMX prevents the chromosome loss in hyperploid cells by inhibiting spindle multipolarity, in that way stimulating genome stability. Thus, under certain conditions MDMX indeed can function as an antioncogene. It would be interesting to investigate whether the reduced MDMX expression in later stage thyroid tumors [79] is correlated with low expression of p $21^{\mathrm{WAF} 1}$ and/or aneuploidy. Recently, two mouse models have been published that overexpress an $m d m x$ transgene. Unfortunately, the mice show different phenotypes, which cannot easily be explained at the moment. In the first model, the generally overexpressed MDMX protein induces spontaneous tumor formation, mostly sarcomas, indicating an oncogene function of MDMX [86]. MDMX overexpression also strongly accelerated the tumor development of p53 heterozygous mice. Unfortunately, the effect of MDMX overexpression was not investigated in a p53-null background. In the light of the study of Jones and colleagues [85], showing that loss of MDMX in p53-null mice accelerates tumor formation, one might predict that overexpression of MDMX should reduce the rate of spontaneous tumor formation in the p53-null mice. Surprisingly, the second $m d m x$ transgenic mouse model, in which a Myc-tagged MDMX is overexpressed, does not accelerate tumor formation, neither the spontaneous nor the $\mathrm{E} \mu$-Myc induced tumorigenesis [87]. Interestingly, only a heterozygous $m y c-m d m x$ transgenic mouse is viable; the homozygous transgenic mice die during embryogenesis in a p53-independent manner, due to massive vascular maturation defects. An in-depth side-byside comparison between the two $m d m x$ transgenic mouse models could possibly explain the observed differences in phenotypes.

In conclusion, most available data suggest that the human $m d m x$ gene functions as an oncogene when overexpressed in tumors still expressing wild-type p53, which is supported by most mouse models. However, the question whether expression of MDMX or alternative MDMX proteins produced by alternative splicing has an oncoprotein or a tumor suppressor protein function in tumors lacking p53 (or p21) or expressing a mutant p53 has still to be answered.

\section{Transcriptional Regulation of MDMX Expression}

Up till recently, it was only Gilkes and colleagues who investigated regulation of transcription initiation of the $m d m x$ gene [88]. They found that, like the $m d m 2 \mathrm{P} 2$ promoter, mitogenic signaling stimulates transcription of the $m d m x$ promoter. Especially two Ets-family binding sites are important in that respect, and the MEK/ERK signaling pathway was found to be involved in the induction of MDMX promoter activity upon growth factor stimulation. Expression of oncogenic $\mathrm{K}$-Ras also activated the MDMX promoter. Importantly, in a panel of colon tumors they find an increasing MDMX expression with tumor stage, and this increased expression of MDMX does correlate to some extent with increased activity of the MAPK pathway as measured by phospho-ERK staining. It is intriguing to note that around $50 \%$ of later stage colon tumors stain positive for MDMX in this study and that approximately $50 \%$ of colon tumors contain p53 mutations. It would have been interesting had the authors determined 
the p53 status of the samples they used for MDMX staining to investigate a putative-negative-correlation.

These results indicate that enhanced mitogenic signaling in tumor cells which have lost p14ARF expression might inhibit the tumor suppressor activity of p53 by enhancing both $m d m x$ and $m d m 2$ gene transcription [ $[88,89]$.

More recently, a new twist to the p53/MDM2/MDMX interactions has been added. Wei and colleagues had reported that the intron 1 of the human $m d m x$ gene contains a p53RE, as identified in a global p53 ChIP experiment [90]. Li et al. were the first to publish that this p53RE indeed mediates transcriptional activation of the $m d m x$ gene upon activation of p53 by Nutlin-3 [91]. Furthermore, they provide evidence that reducing MDMX levels in the TGCT (testicular germ cell tumor) cell line NT2/D1 induces low levels of apoptosis, but strongly sensitizes these cells for growth inhibition by Nutlin-3. However, this effect was not observed in other TGCT cell lines tested. The authors do suggest that in the NT2/D1 cells MDMX is involved in a negative feedback loop, similar to MDM2. These studies do not distinguish between the importance of the constitutive $m d m x$ transcription and the p53-induced transcription. In collaboration with the groups of Jeremy Blaydes and Frank Bartel, we also recently reported that the previous identified p53RE in the first intron of $m d m x$ is directing p53-induced transcription of the $m d m x$ gene [92]. In addition to the earlier publication, we showed that the p53RE initiates transcription from an alternative promoter $(m d m x \mathrm{P} 2)$, which includes an alternative first exon (named exon $1 \beta$ ) in the $m d m x$ mRNA. This exon contains an in-frame upstream ATG relative to the canonical first ATG, which results in the synthesis of 18 extra-N-terminal amino acids. It was found that the $m d m x \mathrm{P} 2$ promoter can be induced in almost all cells tested that express wild-type p53 (only a few primary human cell cultures showed a very low or undetectable expression). Furthermore, every type of p53 activation (Nutlin3, DNA damage, ribosomal stress, Leptomycin B, activation of p14ARF expression) increased transcription from the $m d m x \mathrm{P} 2$ promoter. Most importantly, the inclusion in the $m d m x P 2$ mRNA of a unique exon provided us with the opportunity to investigate specifically the contribution of the p53-induced $m d m x$ mRNA expression in the p53 response. Indeed, shRNA targeting sequences in the unique exon $1 \beta$ increased the p53 response upon treatment of cells with Nutlin-3 or DNA damage (etoposide) and enhanced the p53induced growth inhibition. These results together strongly establish $m d m x$ as a p53 target gene, involved in a negative feedback loop to attenuate the p53 response.

\section{Conclusions and Future Perspectives}

When the identification of the $m d m x$ gene was presented in 1996 [18], the p53 field was not immediately impressed. The added value of MDMX to MDM2 could not be recognized. MDM2 was expected to be sufficient to keep p53 in check and to regulate the p53 response. However, the p53-dependent embryonal lethality of $m d m x$ knockout mice established MDMX as an essential regulator of p53 activity. In more recent years, it has become clear that during development MDM2 is the more general regulator of p53 activity. However, the intricate regulation of MDMX has been shown to be essential for a controlled p53 response upon various forms of stress, as much as MDM2 regulation. Although great insight into regulation of MDMX expression and activity has been obtained, much has still to be learned. How is MDMX degraded upon ribosomal stress, since DNAdamaged induced phosphorylations are not involved? How is the alternative splicing of MDMX upon certain types of genotoxic stress regulated? Do the various identified $m d m x$ mRNAs encode proteins with important biological functions in the coordination of stress response or in tumorigenesis? Under which circumstances is MDMX acting as an oncogene, and when is it stimulating the p53 tumor suppressor response? The answers to these questions will be important for understanding the role of MDMX in tumorigenesis, and for obtaining more insight into the possibility to regard MDMX as a target for therapeutic intervention in cancer.

\section{Acknowledgments}

The authors would like to thank Amina Teunisse and Kirsten Lodder for technical assistance and Dr. Frank Bartel for providing the anti-MDMX-S-specific antibody. This work was supported by a Grant from the Dutch Cancer Society (no. UL 2006-3595).

\section{References}

[1] V. Zuckerman, K. Wolyniec, R. V. Sionov, S. Haupt, and Y. Haupt, "Tumour suppression by p53: the importance of apoptosis and cellular senescence," Journal of Pathology, vol. 219, no. 1, pp. 3-15, 2009.

[2] E. S. Helton and X. Chen, "p53 modulation of the DNA damage response," Journal of Cellular Biochemistry, vol. 100, no. 4, pp. 883-896, 2007.

[3] J. G. Teodoro, S. K. Evans, and M. R. Green, "Inhibition of tumor angiogenesis by p53: a new role for the guardian of the genome," Journal of Molecular Medicine, vol. 85, no. 11, pp. 1175-1186, 2007.

[4] E. Gottlieb and K. H. Vousden, "p53 regulation of metabolic pathways," Cold Spring Harbor Perspectives in Biology, vol. 2, no. 4, Article ID a001040, 2010.

[5] Y. Pan and J. Chen, "Modification of MDMX by sumoylation," Biochemical and Biophysical Research Communications, vol. 332, no. 3, pp. 702-709, 2005.

[6] L. Chen, C. Li, Y. Pan, and J. Chen, "Regulation of p53-MDMX interaction by casein kinase 1 alpha," Molecular and Cellular Biology, vol. 25, no. 15, pp. 6509-6520, 2005.

[7] B. Elias, A. Laine, and Z. Ronai, "Phosphorylation of MdmX by $\mathrm{CDK} 2 / \mathrm{Cdc} 2$ is required for nuclear export of $\mathrm{Mdm} 2$," Oncogene, vol. 24, no. 15, pp. 2574-2579, 2005.

[8] Y. V. Wang, M. Wade, and G. M. Wahl, "Guarding the guardian: Mdmx plays important roles in setting p53 basal activity and determining biological responses in vivo," Cell Cycle, vol. 8, no. 21, pp. 3443-3444, 2009.

[9] M. Wade, Y. V. Wang, and G. M. Wahl, "The p53 orchestra: Mdm2 and Mdmx set the tone," Trends in Cell Biology, vol. 20, no. 5, pp. 299-309, 2010. 
[10] J. C. Marine and G. Lozano, "Mdm2-mediated ubiquitylation: p53 and beyond," Cell Death and Differentiation, vol. 17, no. 1, pp. 93-102, 2010.

[11] V. Böttger, A. Böttger, C. Garcia-Echeverria et al., "Comparative study of the p53-mdm2 and p53-MDMX interfaces," Oncogene, vol. 18, no. 1, pp. 189-199, 1999.

[12] D. A. Sharp, S. A. Kratowicz, M. J. Sank, and D. L. George, "Stabilization of the MDM2 oncoprotein by interaction with the structurally related MDMX protein," The Journal of Biological Chemistry, vol. 274, no. 53, pp. 38189-38196, 1999.

[13] H. Kawai, D. Wiederschain, and Z. M. Yuan, "Critical contribution of the MDM2 acidic domain to p53 ubiquitination," Molecular and Cellular Biology, vol. 23, no. 14, pp. 4939-4947, 2003.

[14] E. Meulmeester, R. Frenk, R. Stad et al., "Critical role for a central part of Mdm2 in the ubiquitylation of p53," Molecular and Cellular Biology, vol. 23, no. 14, pp. 4929-4938, 2003.

[15] N. D. Marchenko, S. Wolff, S. Erster, K. Becker, and U. M. Moll, "Monoubiquitylation promotes mitochondrial p53 translocation," The EMBO Journal, vol. 26, no. 4, pp. 923-934, 2007.

[16] D. Shi, M. S. Pop, R. Kulikov, I. M. Love, A. Kung, and S. R. Grossman, "CBP and p300 are cytoplasmic E4 polyubiquitin ligases for p53," Proceedings of the National Academy of Sciences of the United States of America, vol. 106, no. 38, pp. 1627516280, 2009.

[17] J. T. Lee and W. Gu, "The multiple levels of regulation by p53 ubiquitination," Cell Death and Differentiation, vol. 17, no. 1, pp. 86-92, 2010.

[18] A. Shvarts, W. T. Steegenga, N. Riteco et al., "MDMX: a novel p53-binding protein with some functional properties of MDM2," The EMBO Journal, vol. 15, no. 19, pp. 5349-5357, 1996.

[19] P. Sabbatini and F. Mccormick, "MDMX inhibits the p300/CBP-mediated acetylation of p53," DNA and Cell Biology, vol. 21, no. 7, pp. 519-525, 2002.

[20] D. Danovi, E. Meulmeester, D. Pasini et al., "Amplification of Mdmx (or Mdm4) directly contributes to tumor formation by inhibiting p53 tumor suppressor activity," Molecular and Cellular Biology, vol. 24, no. 13, pp. 5835-5843, 2004.

[21] K. A. Krummel, C. J. Lee, F. Toledo, and G. M. Wahl, "The C-terminal lysines fine-tune P53 stress responses in a mouse model but are not required for stability control or transactivation," Proceedings of the National Academy of Sciences of the United States of America, vol. 102, no. 29, pp. 10188-10193, 2005.

[22] J. Gu, H. Kawai, L. Nie et al., "Mutual dependence of MDM2 and MDMX in their functional inactivation of $\mathrm{p} 53$," The Journal of Biological Chemistry, vol. 277, no. 22, pp. 1925119254, 2002.

[23] H. Kawai, V. Lopez-Pajares, M. M. Kim, D. Wiederschain, and Z. M. Yuan, "RING domain-mediated interaction is a requirement for MDM2's E3 ligase activity," Cancer Research, vol. 67, no. 13, pp. 6026-6030, 2007.

[24] K. Linke, P. D. Mace, C. A. Smith, D. L. Vaux, J. Silke, and C. L. Day, "Structure of the MDM2/MDMX RING domain heterodimer reveals dimerization is required for their ubiquitylation in trans," Cell Death and Differentiation, vol. 15, no. 5, pp. 841-848, 2008.

[25] M. V. Poyurovsky, C. Priest, A. Kentsis et al., "The Mdm2 RING domain C-terminus is required for supramolecular assembly and ubiquitin ligase activity," The EMBO Journal, vol. 26, no. 1, pp. 90-101, 2007.
[26] M. W. Jackson and S. J. Berberich, "Constitutive mdmx expression during cell growth, differentiation, and DNA damage," DNA and Cell Biology, vol. 18, no. 9, pp. 693-700, 1999.

[27] C. Li, L. Chen, and J. Chen, "DNA damage induces MDMX nuclear translocation by p53-dependent and -independent mechanisms," Molecular and Cellular Biology, vol. 22, no. 21, pp. 7562-7571, 2002.

[28] F. Gentiletti, F. Mancini, M. D’Angelo et al., "MDMX stability is regulated by p53-induced caspase cleavage in NIH3T3 mouse fibroblasts," Oncogene, vol. 21, no. 6, pp. 867-877, 2002.

[29] Y. Pan and J. Chen, "MDM2 promotes ubiquitination and degradation of MDMX," Molecular and Cellular Biology, vol. 23, no. 15, pp. 5113-5121, 2003.

[30] P. de Graaf, N. A. Little, Y. F. M. Ramos, E. Meulmeester, S. J. F. Letteboer, and A. G. Jochemsen, "Hdmx protein stability is regulated by the ubiquitin ligase activity of Mdm2," The Journal of Biological Chemistry, vol. 278, no. 40, pp. 38315-38324, 2003.

[31] H. Kawai, D. Wiederschain, H. Kitao, J. Stuart, K. K. C. Tsai, and Z. M. Yuan, "DNA damage-induced MDMX degradation is mediated by MDM2," The Journal of Biological Chemistry, vol. 278, no. 46, pp. 45946-45953, 2003.

[32] L. Chen, D. M. Gilkes, Y. Pan, W. S. Lane, and J. Chen, "ATM and Chk2-dependent phosphorylation of MDMX contribute to p53 activation after DNA damage," The EMBO Journal, vol. 24, no. 19, pp. 3411-3422, 2005.

[33] Y. Pereg, D. Shkedy, P. de Graaf et al., "Phosphorylation of Hdmx mediates its Hdm2- and ATM-dependent degradation in response to DNA damage," Proceedings of the National Academy of Sciences of the United States of America, vol. 102, no. 14, pp. 5056-5061, 2005.

[34] K. Okamoto, K. Kashima, Y. Pereg et al., "DNA damageinduced phosphorylation of MdmX at serine 367 activates p53 by targeting MdmX for Mdm2-dependent degradation," Molecular and Cellular Biology, vol. 25, no. 21, pp. 9608-9620, 2005.

[35] Y. Pereg, S. Lam, A. Teunisse et al., "Differential roles of ATMand Chk2-mediated phosphorylations of Hdmx in response to DNA damage," Molecular and Cellular Biology, vol. 26, no. 18, pp. 6819-6831, 2006.

[36] C. LeBron, L. Chen, D. M. Gilkes, and J. Chen, "Regulation of MDMX nuclear import and degradation by Chk2 and 14-3-3," The EMBO Journal, vol. 25, no. 6, pp. 1196-1206, 2006.

[37] E. Meulmeester, M. M. Maurice, C. Boutell et al., "Loss of HAUSP-mediated deubiquitination contributes to DNA damage-induced destabilization of $\mathrm{Hdmx}$ and $\mathrm{Hdm} 2$," Molecular Cell, vol. 18, no. 5, pp. 565-576, 2005.

[38] F. Sarkari, A. La Delfa, C. H. Arrowsmith, L. Frappier, Y. Sheng, and V. Saridakis, "Further insight into substrate recognition by USP7: structural and biochemical analysis of the HdmX and Hdm2 interactions with USP7," Journal of Molecular Biology, vol. 402, no. 5, pp. 825-837, 2010.

[39] N. T. Wood, D. W. Meek, and C. MacKintosh, "14-3-3 Binding to Pim-phosphorylated Ser166 and Ser186 of human Mdm2-potential interplay with the $\mathrm{PKB} /$ Akt pathway and p14," FEBS Letters, vol. 583, no. 4, pp. 615-620, 2009.

[40] W. Yang, D. T. Dicker, J. Chen, and W. S. El-Deiry, "CARPs enhance p53 turnover by degrading $14-3-3 \sigma$ and stabilizing MDM2," Cell Cycle, vol. 7, no. 5, pp. 670-682, 2008.

[41] J. M. Stommel and G. M. Wahl, "Accelerated MDM2 autodegradation induced by DNA-damage kinases is required for p53 activation," The EMBO Journal, vol. 23, no. 7, pp. 1547-1556, 2004. 
[42] Y. Jin, M. S. Dai, S. Z. Lu et al., "14-3-3 $\gamma$ binds to MDMX that is phosphorylated by UV-activated Chk1, resulting in p53 activation," The EMBO Journal, vol. 25, no. 6, pp. 1207-1218, 2006.

[43] Y. V. Wang, M. Leblanc, M. Wade, A. G. Jochemsen, and G. M. Wahl, "Increased Radioresistance and Accelerated B Cell Lymphomas in Mice with Mdmx Mutations that Prevent Modifications by DNA-Damage-Activated Kinases," Cancer Cell, vol. 16, no. 1, pp. 33-43, 2009.

[44] V. Zuckerman, K. Lenos, G. M. Popowicz et al., "c-Abl phosphorylates Hdmx and regulates its interaction with p53," The Journal of Biological Chemistry, vol. 284, no. 6, pp. 4031-4039, 2009.

[45] F. Bartel, H. Taubert, and L. C. Harris, "Alternative and aberrant splicing of MDM2 mRNA in human cancer," Cancer Cell, vol. 2, no. 1, pp. 9-15, 2002.

[46] F. Mancini, G. Di Conza, and F. Moretti, "MDM4 (MDMX) and its transcript variants," Current Genomics, vol. 10, no. 1, pp. 42-50, 2009.

[47] D. S. Chandler, R. K. Singh, L. C. Caldwell, J. L. Bitler, and G. Lozano, "Genotoxic stress induces coordinately regulated alternative splicing of the p53 modulators MDM2 and MDM4," Cancer Research, vol. 66, no. 19, pp. 9502-9508, 2006.

[48] R. Rallapalli, G. Strachan, B. Cho, W. E. Mercer, and D. J. Hall, "A novel MDMX transcript expressed in a variety of transformed cell lines encodes a truncated protein with potent p53 repressive activity," The Journal of Biological Chemistry, vol. 274, no. 12, pp. 8299-8308, 1999.

[49] R. Rallapalli, G. Strachan, R. S. Tuan, and D. J. Hall, "Identification of a domain within MDMX-S that is responsible for its high affinity interaction with p53 and high-level expression in mammalian cells," Journal of Cellular Biochemistry, vol. 89, no. 3, pp. 563-575, 2003.

[50] W. van der Houven van Oordt, M. T. Diaz-Meco, J. Lozano, A. R. Krainer, J. Moscat, and J. F. Cáceres, "The MKK(3/6)-p38signaling cascade alters the subcellular distribution of hnRNP A1 and modulates alternative splicing regulation," Journal of Cell Biology, vol. 149, no. 2, pp. 307-316, 2000.

[51] N. Shomron, M. Alberstein, M. Reznik, and G. Ast, "Stress alters the subcellular distribution of hSlu7 and thus modulates alternative splicing," Journal of Cell Science, vol. 118, no. 6, pp. 1151-1159, 2005.

[52] M. J. Muñoz, M. S. P. Santangelo, M. P. Paronetto et al., "DNA damage regulates alternative splicing through inhibition of RNA polymerase II elongation," Cell, vol. 137, no. 4, pp. 708-720, 2009.

[53] F. Mancini, G. Di Conza, M. Pellegrino et al., "MDM4 (MDMX) localizes at the mitochondria and facilitates the p53-mediated intrinsic-apoptotic pathway," The EMBO Journal, vol. 28, no. 13, pp. 1926-1939, 2009.

[54] M. Markey and S. J. Berberich, "Full-length hdmX transcripts decrease following genotoxic stress," Oncogene, vol. 27, no. 52, pp. 6657-6666, 2008.

[55] T. C. Chang, E. A. Wentzel, O. A. Kent et al., "Transactivation of miR-34a by p53 broadly influences gene expression and promotes apoptosis," Molecular Cell, vol. 26, no. 5, pp. 745-752, 2007.

[56] N. Raver-Shapira, E. Marciano, E. Meiri et al., "Transcriptional activation of miR-34a contributes to p53-mediated apoptosis," Molecular Cell, vol. 26, no. 5, pp. 731-743, 2007.

[57] F. Mancini, F. Gentiletti, M. D’Angelo et al., "MDM4 (MDMX) overexpression enhances stabilization of stressinduced p53 and promotes apoptosis," The Journal of Biological Chemistry, vol. 279, no. 9, pp. 8169-8180, 2004.
[58] F. Bunz, P. M. Hwang, C. Torrance et al., "Disruption of p53 in human cancer cells alters the responses to therapeutic agents," Journal of Clinical Investigation, vol. 104, no. 3, pp. 263-269, 1999.

[59] M. E. Perry, J. Piette, J. A. Zawadzki, D. Harvey, and A. J. Levine, "The mdm-2 gene is induced in response to UV light in a p53-dependent manner," Proceedings of the National Academy of Sciences of the United States of America, vol. 90, no. 24, pp. 11623-11627, 1993.

[60] M. Ashcroft, Y. Taya, and K. H. Vousden, "Stress signals utilize multiple pathways to stabilize p53," Molecular and Cellular Biology, vol. 20, no. 9, pp. 3224-3233, 2000.

[61] Y. Wang, K. M. Debatin, and H. Hug, "HIPK2 overexpression leads to stabilization of p53 protein and increased p53 transcriptional activity by decreasing Mdm2 protein levels," BMC Molecular Biology, vol. 2, article 8, 2001.

[62] V. Di Stefano, G. Blandino, A. Sacchi, S. Soddu, and G. D’Orazi, "HIPK2 neutralizes MDM2 inhibition rescuing p53 transcriptional activity and apoptotic function," Oncogene, vol. 23, no. 30, pp. 5185-5192, 2004.

[63] L. F. Z. Batista, W. P. Roos, B. Kaina, and C. F. M. Menck, "p53 mutant human glioma cells are sensitive to UV-Cinduced apoptosis due to impaired cyclobutane pyrimidine dimer removal," Molecular Cancer Research, vol. 7, no. 2, pp. 237-246, 2009.

[64] D. Debernardis, E. G. Siré, P. de Feudis et al., "p53 status does not affect sensitivity of human ovarian cancer cell lines to paclitaxel," Cancer Research, vol. 57, no. 5, pp. 870-874, 1997.

[65] E. Shankar, C. Basu, B. Adkins, W. Siede, and A. Basu, "NSC109268 potentiates cisplatin-induced cell death in a p53-independent manner," Journal of Molecular Signaling, vol. 5, article 4, 2010.

[66] C. P. Rubbi and J. Milner, "Disruption of the nucleolus mediates stabilization of p53 in response to DNA damage and other stresses," The EMBO Journal, vol. 22, no. 22, pp. 6068-6077, 2003.

[67] C. Deisenroth and Y. Zhang, "Ribosome biogenesis surveillance: probing the ribosomal protein-Mdm2-p53 pathway," Oncogene, vol. 29, pp. 4253-4260, 2010.

[68] Y. Zhang and H. Lu, "Signaling to p53: ribosomal proteins find their way," Cancer Cell, vol. 16, no. 5, pp. 369-377, 2009.

[69] D. M. Gilkes, L. Chen, and J. Chen, "MDMX regulation of p53 response to ribosomal stress," The EMBO Journal, vol. 25, no. 23, pp. 5614-5625, 2006.

[70] A. A. Thant, Y. Wu, J. Lee et al., "Role of caspases in 5-FU and selenium-induced growth inhibition of colorectal cancer cells," Anticancer Research, vol. 28, no. 6 A, pp. 3579-3592, 2008.

[71] S. Lam, K. Lodder, A. F. A. S. Teunisse, M. J. W. E. Rabelink, M. Schutte, and A. G. Jochemsen, "Role of Mdm4 in drug sensitivity of breast cancer cells," Oncogene, vol. 29, no. 16, pp. 2415-2426, 2010.

[72] M. Derenzini, E. Brighenti, G. Donati et al., "The p53mediated sensitivity of cancer cells to chemotherapeutic agents is conditioned by the status of the retinoblastoma protein," Journal of Pathology, vol. 219, no. 3, pp. 373-382, 2009.

[73] Y. Zhu, M. V. Poyurovsky, Y. Li et al., "Ribosomal protein S7 is both a regulator and a substrate of MDM2," Molecular Cell, vol. 35, no. 3, pp. 316-326, 2009.

[74] S. Giglio, F. Mancini, F. Gentiletti et al., "Identification of an aberrantly spliced form of HDMX in human tumors: a new mechanism for HDM2 stabilization," Cancer Research, vol. 65, no. 21, pp. 9687-9694, 2005. 
[75] R. Stad, Y. F. M. Ramos, N. Little et al., "Hdmx stabilizes Mdm2 and p53," The Journal of Biological Chemistry, vol. 275, no. 36, pp. 28039-28044, 2000.

[76] F. Moretti, S. Nanni, A. Farsetti et al., "Effects of exogenous p53 transduction in thyroid tumor cells with different p53 status," Journal of Clinical Endocrinology and Metabolism, vol. 85, no. 1, pp. 302-308, 2000.

[77] M. J. Riemenschneider, R. Büschges, M. Wolter et al., "Amplification and overexpression of the MDM4 (MDMX) gene from 1q32 in a subset of malignant gliomas without TP53 mutation or MDM2 amplification," Cancer Research, vol. 59, no. 24, pp. 6091-6096, 1999.

[78] F. Bartel, J. Schulz, A. Böhnke et al., "Significance of HDMX-S (or MDM4) mRNA splice variant overexpression and HDMX gene amplification on primary soft tissue sarcoma prognosis," International Journal of Cancer, vol. 117, no. 3, pp. 469-475, 2005.

[79] A. Prodosmo, S. Giglio, S. Moretti et al., "Analysis of human MDM4 variants in papillary thyroid carcinomas reveals new potential markers of cancer properties," Journal of Molecular Medicine, vol. 86, no. 5, pp. 585-596, 2008.

[80] G. Jin, S. Cook, B. Cui et al., "HDMX regulates p53 activity and confers chemoresistance to 3-bis(2-chloroethyl)-1nitrosourea," Neuro-Oncology, vol. 12, no. 9, pp. 956-966, 2010.

[81] M. D. Bo, P. Secchiero, M. Degan et al., "MDM4 (MDMX) is overexpressed in chronic lymphocytic leukaemia (CLL) and marks a subset of p53 CLL with a poor cytotoxic response to Nutlin-3," British Journal of Haematology, vol. 150, no. 2, pp. 237-239, 2010.

[82] Y. A. Valentin-Vega, J. A. Barboza, G. P. Chau, A. K. El-Naggar, and G. Lozano, "High levels of the p53 inhibitor MDM4 in head and neck squamous carcinomas," Human Pathology, vol. 38, no. 10, pp. 1553-1562, 2007.

[83] X. Han, G. Garcia-Manero, T. J. McDonnell et al., "HDM4 (HDMX) is widely expressed in adult pre-B acute lymphoblastic leukemia and is a potential therapeutic target," Modern Pathology, vol. 20, no. 1, pp. 54-62, 2007.

[84] H. A. Steinman, H. K. Sluss, A. T. Sands, G. Pihan, and S. $\mathrm{N}$. Jones, "Absence of p21 partially rescues Mdm4 loss and uncovers an antiproliferative effect of Mdm4 on cell growth," Oncogene, vol. 23, no. 1, pp. 303-306, 2004.

[85] Z. Matijasevic, H. A. Steinman, K. Hoover, and S. N. Jones, "MDMX promotes bipolar mitosis to suppress transformation and tumorigenesis in p53-deficient cells and mice," Molecular and Cellular Biology, vol. 28, no. 4, pp. 1265-1273, 2008.

[86] S. Xiong, V. Pant, Y.-A. Suh et al., "Spontaneous tumorigenesis in mice overexpressing the p53-negative regulator Mdm4," Cancer Research, vol. 70, no. 18, pp. 7148-7154, 2010.

[87] S. de Clercq, A. Gembarska, G. Denecker et al., "Widespread overexpression of epitope-tagged Mdm4 does not accelerate tumor formation in vivo," Molecular and Cellular Biology, vol. 30, no. 22, pp. 5394-5405, 2010.

[88] D. M. Gilkes, Y. Pan, D. Coppola, T. Yeatman, G. W. Reuther, and J. Chen, "Regulation of MDMX expression by mitogenic signaling," Molecular and Cellular Biology, vol. 28, no. 6, pp. 1999-2010, 2008.

[89] S. Ries, C. Biederer, D. Woods et al., "Opposing effects of RAS on p53: transcriptional activation of $\mathrm{mdm} 2$ and induction of p19(ARF)," Cell, vol. 103, no. 2, pp. 321-330, 2000.

[90] C. L. Wei, Q. Wu, V. B. Vega et al., "A global map of p53 transcription-factor binding sites in the human genome," Cell, vol. 124, no. 1, pp. 207-219, 2006.
[91] B. Li, Q. Cheng, Z. Li, and J. Chen, "p53 inactivation by MDM2 and MDMX negative feedback loops in testicular germ cell tumors," Cell Cycle, vol. 9, no. 7, pp. 1411-1420, 2010.

[92] A. Phillips, A. Teunisse, S. Lam et al., "HDMX-L is expressed from a functional $\mathrm{p} 53$-responsive promoter in the first intron of the HDMX gene and participates in an autoregulatory feedback loop to control p53 activity," The Journal of Biological Chemistry, vol. 285, no. 38, pp. 29111-29127, 2010. 



Submit your manuscripts at

http://www.hindawi.com
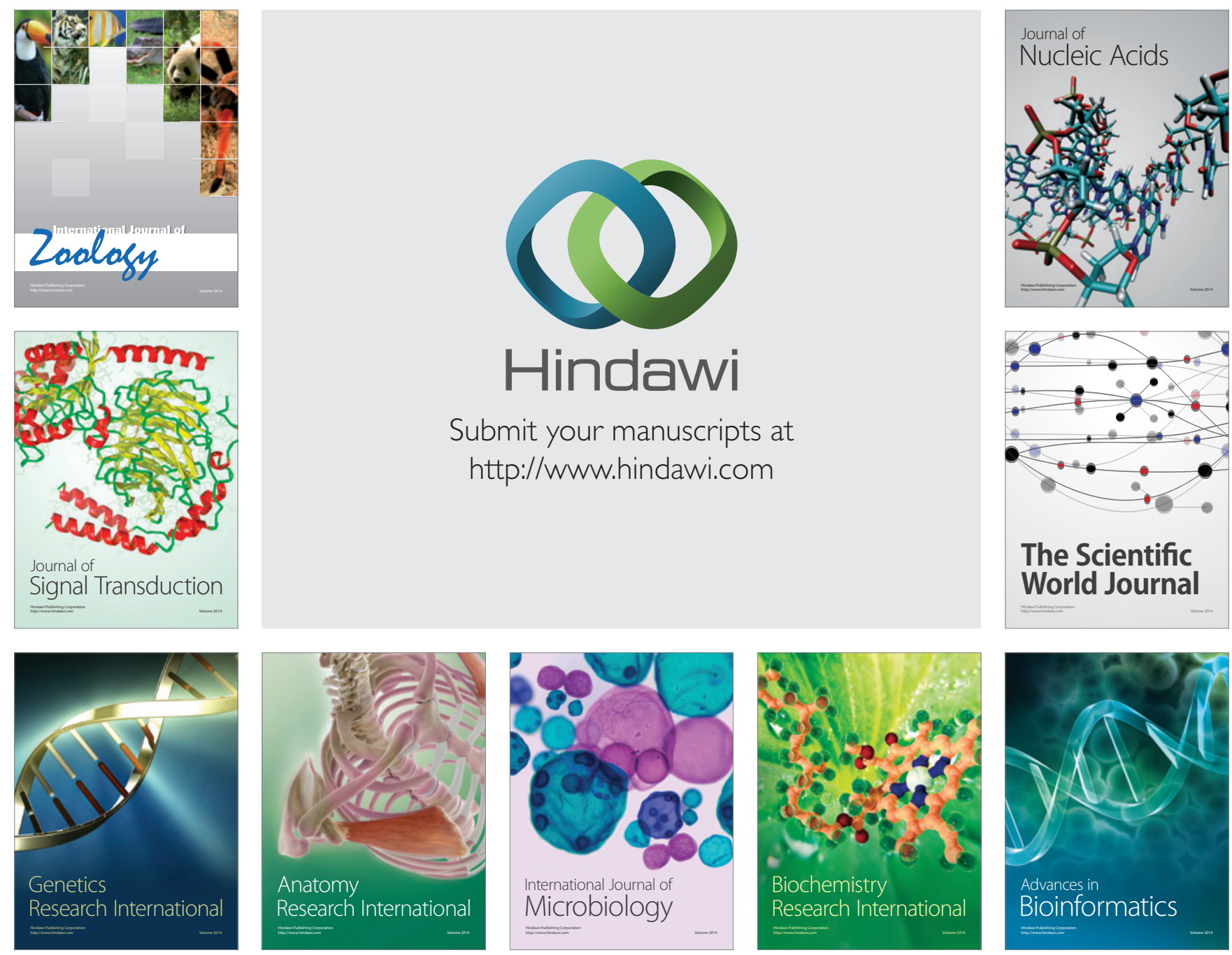

The Scientific World Journal
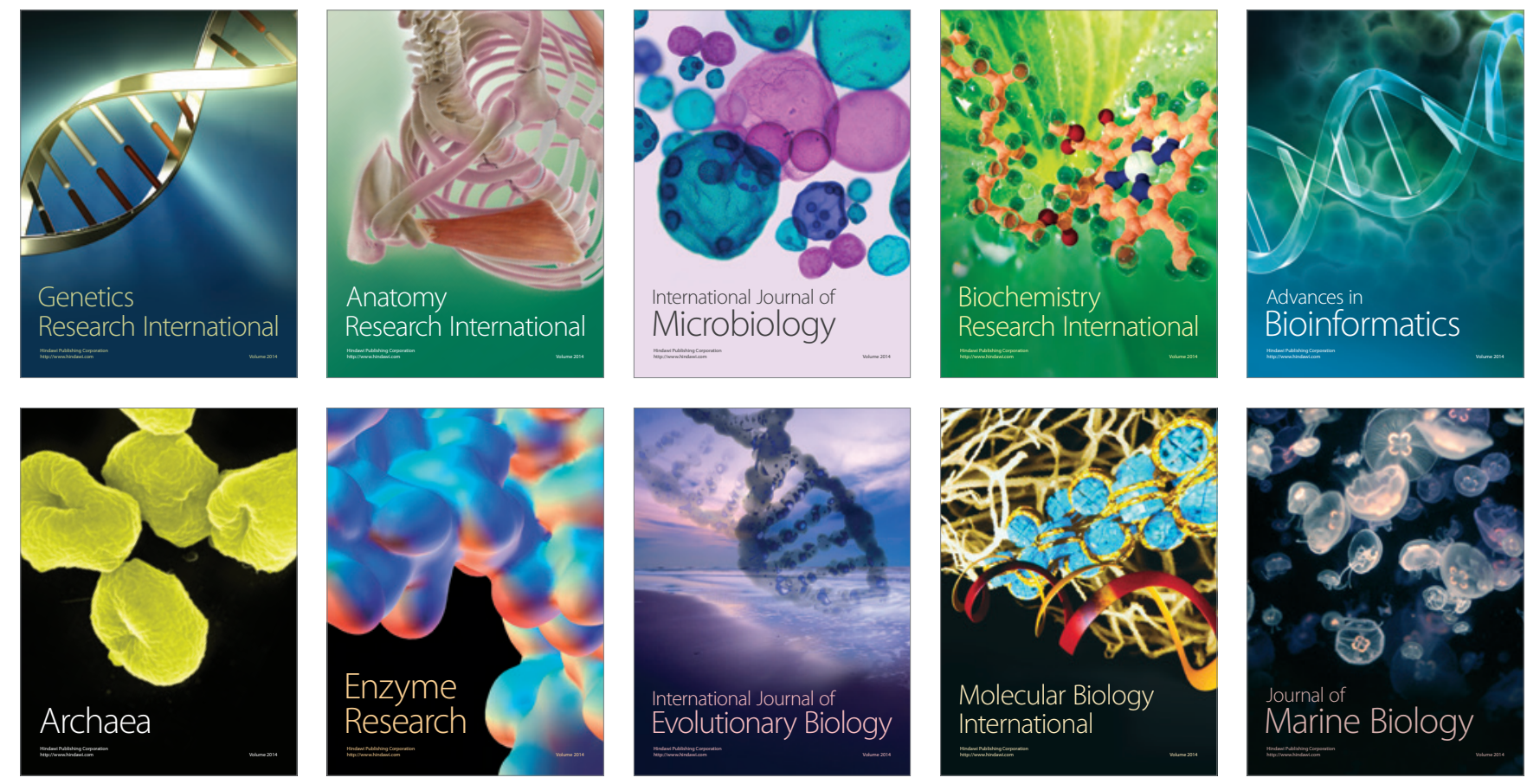